\title{
A CONTRIBUIÇÃO DO PRÉ-NATAL PARA O PARTO E NASCIMENTO
}

\section{THE CONTRIBUTION OF PRENATAL FOR BIRTH AND LABOR}

\author{
Priscila Possidonio $^{1}$, Patrícia Andréia Dombrowski ${ }^{{ }^{*}}$ \\ ${ }^{1}$ Faculdades União Paranaense De Ensino E Cultura- Unipec Integradas Santa Cruz-Faresc \\ - Curitiba, Paraná, Brasil. \\ *Autor correspondente: Patrícia Andréia Dombrowski. Endereço Institucional: UNIÃO \\ PARANAENSE DE ENSINO E CULTURA - UNIPEC, FACULDADES INTEGRADAS \\ SANTA CRUZ - FARESC. Rua Affife Mansur, 565 - Novo Mundo, Curitiba - PR, Brasil, \\ CEP 81050-180. Telefone: (41) 99194-5292.E-mail: paty.ad@uol.com.br
}

\section{RESUMO}

O estudo foi realizado em maio de 2017 , e teve como objetivos analisar e identificar o nível das informações a respeito do trabalho de parto e nascimento, recebidas pelas pacientes atendidas na Maternidade do Bairro Novo, durante o pré-natal, nas unidades básicas de saúde, pela atenção primária com estratificação de risco habitual sobre parto e nascimento. Tal intento foi possível por meio de pesquisas de campo e comparação a práticas de educação em saúde, levantadas para verificar a conformidade e integralidade de tais informações. A coleta das informações foi realizada durante um mês, com gestantes do terceiro trimestre de risco habitual, atendidas na Maternidade do Bairro Novo. As análises dos dados foram feitas no Software Excel, onde houve a comparação e conversão dos resultados em porcentagem. Os resultados obtidos foram utilizados para estabelecer se as informações recebidas, pelas gestantes em questão, nas unidades de saúde, estavam de acordo com as melhores práticas de educação em saúde e indicar possibilidades e caminhos para melhorias, uma vez que muitas das entrevistadas ainda apresentavam dúvidas sobre orientações nos processos do pré-natal e após o nascimento, ficando nítido que as gestantes sofriam com essa carência de informação na gestação e no seu puerpério.

Palavras-chave: Cuidado Pré-natal - Humanização da assistência - Educação em Saúde - Parto.

The study was carried out in May 2017 and had as object of study the information about labor and delivery, received by the patients of the Maternidade do Bairro Novo during prenatal care in the basic health units. The objective was to identify the level of prenatal information received by these low-risk pregnant women about birth and delivery through field surveys and compare them with health education practices raised to verify compliance and completeness of such information. The data collection was performed during one month with pregnant women of the third quarter of habitual risk attended at the Maternidade do Bairro Novo. Statistical analyzes were done in Excel software. The results obtained were used to establish if the information received by the pregnant women in question in the health units are in accordance with the best practices of health education and indicate possibilities and paths for improvements

Key words: Prenatal Care - Information - Humanization - Health - Childbirth Education 


\section{INTRODUÇÃO}

As gestantes buscam informações, por meio de atendimento com os profissionais da saúde, a fim de tirar suas dúvidas e realizar exames para a confirmação de que está tudo correndo bem com a sua gestação, tudo isso no pré-natal. De acordo com a Comissão Nacional de Incorporação de Tecnologias do SUS (CONITEC 2016), quando as mulheres procuram ajuda, além da preocupação com a sua saúde e a do seu filho, estão também em busca de orientações, pois para a gestante e sua família, o momento da gravidez e do parto, em particular, é único. A experiência vivida por eles, neste momento, pode deixar marcas positivas ou negativas, para o resto das suas vidas. Sendo assim, essas orientações devem existir para proporcionar um parto tranquilo e, sobretudo, que a mulher seja a protagonista da história.

É muito importante que a equipe de enfermagem, da unidade básica de saúde, esteja preparada para realizar o pré-natal. E saber determinar, desde o estado emocional da paciente e dos familiares no momento do parto, até explicar quais são os procedimentos, os direitos e deveres da gestante e do seu acompanhante, possibilitando uma maior participação da gestante no próprio trabalho de parto. O importante é que a gestante e seus familiares saibam a respeito do andamento do trabalho de parto, realizando-se conversas e orientações, por parte da equipe de enfermagem, e que se tenha paciência necessária para garantir o melhor parto possível à mãe e ao bebê (MAMEDE et al., 2007).

Deve-se destacar o papel de cada profissional envolvido no pré-natal, para conseguir a preparação necessária à gestante e seus familiares, quando do momento do nascimento do bebê, bem como a relevância da sociedade e da cultura popular no reconhecimento das orientações fornecidas.

Este estudo tem por objetivo identificar o nível das informações de pré-natal, recebidas pelas gestantes, acolhidas pela atenção primária com estratificação de risco habitual sobre o parto e nascimento, por meio de pesquisas de campo e compará-las às práticas de educação em saúde, levantadas para verificar a conformidade e integralidade de tais informações. Essas informações coletadas, quando colocadas sob o prisma do que é determinado pelo protocolo Mãe Curitibana, fornecerão uma visão clara da eficiência e efetividade do processo e poderão servir como base para posteriores ações corretivas.

O trabalho justifica-se pela importância em verifica se as ações educativas, que as gestantes deveriam receber no pré-natal estão sendo oferecidas corretamente, nas unidades básicas de saúde, tanto no que diz respeito aos procedimentos, vinculações e características da maternidade, quanto aos direitos e deveres das pacientes, que são essenciais para o parto ser uma experiência completa e agradável.

Qual é o nível de informação e orientação que as gestantes estão recebendo, nas unidades básicas de saúde, no pré-natal, a respeito do parto e nascimento de seus filhos?

A hipótese estudada é a de que as gestantes estão recebendo um nível baixo de informação e orientação, durante o pré-natal, o que afeta negativamente a experiência do parto.

\section{MATERIAL E MÉTODOS}

Neste estudo, o método utilizado para determinar o nível de informação das gestantes, a respeito do parto e nascimento, recebido no pré-natal, nas unidades básicas de saúde, e a conformidade com o Programa Mãe Curitibana (2012) foi o descritivo de campo. O estudo foi realizado na Maternidade Bairro Novo, localizada no bairro Sítio Cercado, na cidade de Curitiba. Os indivíduos do estudo foram gestantes de risco habitual, com os seguintes critérios de inclusão: idade acima de 18 anos e terceiro trimestre de gestação. Foram excluídas da pesquisa: gestantes menores de idade ou abaixo do terceiro trimestre de gestação. $O$ contingente para o estudo foi de 25 indivíduos $(\mathrm{n}=25)$, escolhidos aleatoriamente. A coleta de dados ocorreu na maternidade, em maio de 2017. Antes de iniciar as coletas de dados, foi necessária a aprovação pelo Comitê de Ética do Hospital Paranaense de Otorrinolaringologia (IPO), parecer número 1.874.259, e na Secretaria Municipal de Saúde de Curitiba, parecer número 2.027 .765 para a realização da pesquisa, também foi necessário um Termo de Consentimento Livre e Esclarecido (TCLE) que foi entregue aos responsáveis, acompanhado de carta de autorização da Fundação Estatal de Atenção Especializada em Saúde de Curitiba, gestora da Maternidade Bairro Novo.

A coleta foi realizada em duas fases: na $1^{\text {a }}$ fase houve a identificação do atendimento dos critérios de inclusão e exclusão, no momento do atendimento da 
paciente no pronto atendimento da maternidade. $\mathrm{Na}$ $2^{\mathrm{a}}$ fase foi aplicado formulário, contendo 10 questões objetivas, a respeito das orientações e informações recebidas pelas pacientes, durante o pré-natal, nas unidades de saúde.

Essa última fase foi realizada individualmente, em ambiente restrito, e não houve identificação dos pesquisados, a fim de preservar a privacidade dos mesmos. A aplicação do formulário foi realizada pela própria pesquisadora. A análise dos dados foi feita no Software Excel, com lançamento dos dados, geração de gráficos e relatórios. As informações obtidas possibilitaram estabelecer o nível de atendimento dos requisitos de educação em saúde e podem servir como base para projetos posteriores.

\section{RESULTADOS E DISCUSSÃO}

Gráfico 1: Número de consultas de pré-natal.

Consultas de Pré-natal realizadas

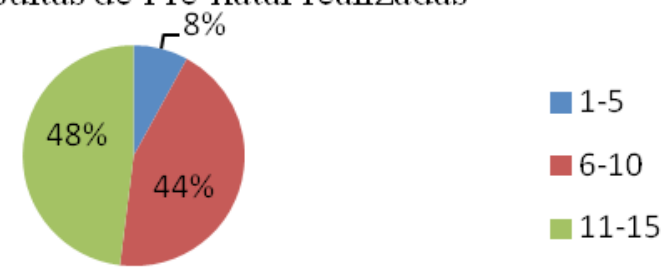

Fonte: Dados da pesquisa realizada na Maternidade do Bairro Novo com 25 gestantes de risco habitual, em maio de 2017.

Em relação ao número de consultas no pré-natal, $48 \%$ do total de entrevistadas tiveram entre 11 e 15 consultas, $44 \%$ tiveram entre 6 e 10 ; e $8 \%$ das entrevistadas tiveram menos de 5 consultas.

Enfatizando a importância dessas consultas, Zampieri et al. (2010) afirmam que o pré-natal busca, sobretudo, avaliar a saúde da mulher, do feto e seu desenvolvimento, em todas as dimensões, encontrando fatores de risco que possam impedir o curso normal da gravidez e possibilitando o correto encaminhamento da gestante para níveis de referências de maior complexidade, que possibilitem a ela a prevenção e/ ou tratamento precoce de complicações. Barreto et al. (2013) complementam que as orientações de cuidados no pré-natal, fornecidas pela enfermeira da unidade de saúde, abarcam cuidados relativos à alimentação, ao repouso, atividade física, controle do peso, medicação, entre outros. Barreto et al. (2013, apud Ministério da
Saúde, 2006) ressaltam a importância de iniciar a consulta de forma precoce, realizar um número mínimo de seis consultas e iniciar atividades educativas.

Portanto, apenas $8 \%$ das gestantes entrevistadas realizaram um número de consultas abaixo do mínimo recomendado pelo Ministério da Saúde, as $92 \%$ restantes; realizaram 6 ou mais consultas durante o pré-natal.

Gráfico 2: Profissional realizador das consultas do prénatal.

Com quem foram as consultas de pré natal?

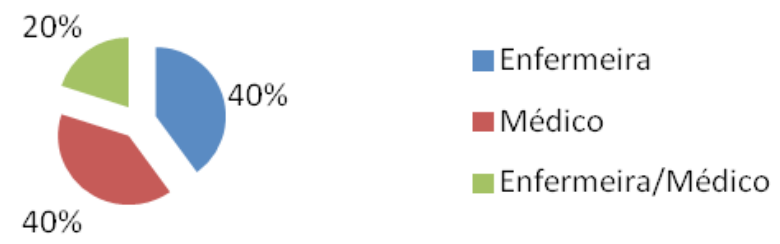

Fonte: Dados da pesquisa realizada na Maternidade do Bairro Novo com 25 gestantes de risco habitual, em maio de 2017.

Quanto ao profissional realizador das consultas de pré-natal, $40 \%$ do total de entrevistadas tiveram mais consultas com enfermeira(o), 40\% consultaram mais com médico(a) e $20 \%$ tiverem consultas intercaladas, tanto com médicos, quanto com enfermeiros.

Um acompanhamento multiprofissional do pré-natal é proposto por Zampieri et al. (2010), ao afirmarem que, apesar de algumas gestantes limitarem o cuidado pré-natal à consulta, a maioria delas necessitaria de consultas, ações educativas e visitas domiciliares, além da consulta médica ou de enfermagem.

Já o protocolo Mãe Curitibana (2012) estipula um número mínimo de 4 consultas médicas e 3 de enfermagem, como parâmetro de qualidade em assistência de pré-natal. Enfatizando a realização de consultas, tanto com o médico, quanto com a enfermeira.

Sendo assim, apenas $20 \%$ das pacientes tiveram as consultas de pré-natal de acordo com o recomendado, contemplando consultas com os dois profissionais, já que as outras $80 \%$ consultaram mais com um ou com outro profissional. 
Gráfico 3: Participação do acompanhante no pré-natal.

Participação do acompanhante no pré-natal

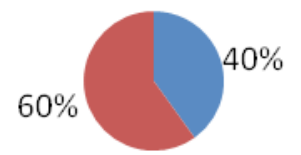

- Não

Sim

Fonte: Dados da pesquisa realizada na Maternidade do Bairro Novo com 25 gestantes de risco habitual, em maio de 2017.

De acordo com a pesquisa, $60 \%$ do total de entrevistadas tiveram a presença do acompanhante na realização do pré-natal, enquanto $40 \%$ não contaram com acompanhante nas consultas. Conforme Reberte e Hoga (2010), é comprovado o fato de que as gestantes, cujos acompanhantes, sendo o marido ou o parceiro, participaram das atividades de educação para a saúde no pré-natal, apresentaram comportamentos melhores em relação aos cuidados com a saúde, se comparadas àquelas que não puderam contar com esta adesão, pelo fato dos acompanhantes oferecerem suporte à mulher, no parto, e colaborarem com a equipe de saúde. Além do entendimento das alterações que, porventura, ocorressem durante o ciclo gravídico e puerperal, por parte do marido, no sentido de produzir reflexos positivos sobre a relação do casal.

Figueiredo e Marques (2011) complementam afirmando que a inserção do homem na consulta de pré-natal pode contribuir para o relacionamento entre pai-filho. Portanto, os profissionais devem incentivar o acompanhamento por parte do pai e o envolvimento deste no processo gravídico. O enfermeiro como integrante da equipe de saúde e um dos responsáveis pela realização do pré-natal, na rede básica de saúde, deve proporcionar o acolhimento do pai na unidade para que possa integrar-se ao processo gestacional.

Dessa forma, tendo em vista a importância do acompanhamento das pacientes nesta fase, percebe-se a necessidade de mais inclusão e participação dos acompanhantes, pois quase a metade das pesquisadas não contaram com a presença desses no pré-natal. Notou-se também, durante as entrevistas, o fato de poucas gestantes estarem com seus acompanhantes.
Gráfico 4: Participação em oficinas na unidade de saúde durante o pré-natal.

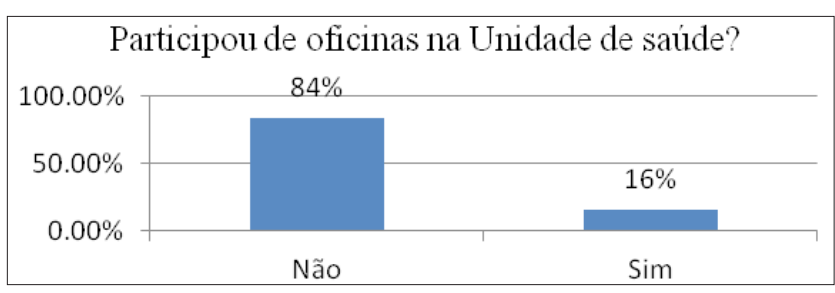

Fonte: Dados da pesquisa realizada na Maternidade do Bairro Novo com 25 gestantes de risco habitual, em maio de 2017.

A pesquisa mostra que $84 \%$ do total de entrevistadas não participaram de oficinas na unidade de saúde, enquanto que $16 \%$ participaram de tais eventos. Como ressaltam Duarte et al (2011), a educação em saúde no pré-natal é um meio para que os profissionais desta área, especialmente os enfermeiros que realizam a primeira consulta de pré-natal, possam dotar as mulheres e seus familiares de conhecimentos, além de esclarecerem as dúvidas, contribuindo para com a autonomia do cuidado.

Lima et al (2014, p 99) concluíram que uma oficina experimental com o tema pré-natal:

Repercutiu de forma positiva entre as participantes, pois suas dúvidas foram respondidas e estas afirmaram estar mais tranquilas e seguras apesar de muitas não estarem na sua primeira gestação. Todos os resultados alcançados demonstraram plenamente, sob diferentes olhares e pontos de vista, que a realização desta oficina se revelou de grande valia, visto que percebemos uma carência de assistência multiprofissional e interprofissional às gestantes, que nesta fase da vida, encontram-se necessitadas de informações e apoio.

São inegáveis os benefícios que os conhecimentos adquiridos, nas oficinas e ações de educação em saúde, trazem. Nota-se, portanto, uma deficiência nesse quesito no que tange ao universo da pesquisa, pois a grande maioria das entrevistadas não participou de oficinas durante o pré-natal.

Gráfico 5: Orientação para visitar a maternidade.

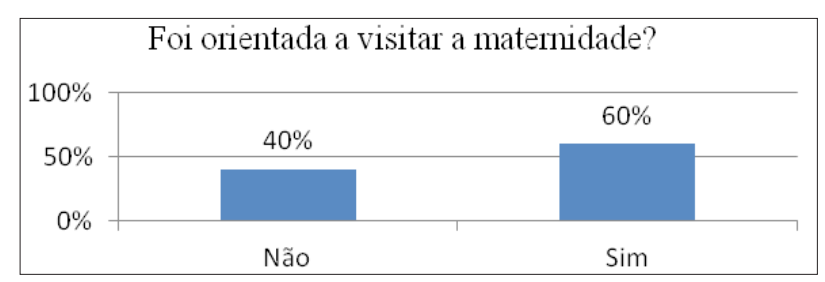

Fonte: Dados da pesquisa realizada na Maternidade do Bairro Novo com 25 gestantes de risco habitual, em maio de 2017. 
Ainda em relação à educação em saúde, $60 \%$ do total de entrevistadas declararam ter sido orientadas a visitar a maternidade e $40 \%$ afirmaram que não tiveram essa orientação. O Protocolo Mãe Curitibana (2012) estabelece que deve ser ofertada e incentivada a participação do casal nas oficinas de pré-natal. Os Distritos Sanitários devem estruturar ciclos de oficinas aos sábados ou à noite, com temas variados, de acordo com a idade gestacional, para as gestantes e os pais. .O pai, junto à gestante, deve ser convidado para as visitas programadas à maternidade de vinculação.

A respeito do objetivo da visita à maternidade, uma enfermeira citada por Sé (2014, p 73) corrobora: "Nós temos ainda a atribuição dessas oficinas educativas para a mulher conhecer a unidade que ela é referenciada e saber em que momento vai buscar a emergência para justamente não ficar peregrinando".

A visita à maternidade é importante, bem como todas as ações de educação em saúde, para preparar as gestantes e tornar a experiência do nascimento agradável e completa. Porém, na pesquisa realizada, grande parte das gestantes não foi orientada a conhecer a maternidade antes do parto.

Gráfico 6: Sinais de trabalho de parto.

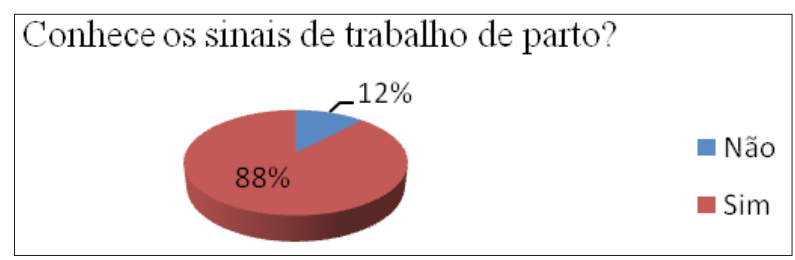

Fonte: Dados da pesquisa realizada na Maternidade do Bairro Novo com 25 gestantes de risco habitual, em maio de 2017.

De acordo com a pesquisa, $88 \%$ do total de entrevistadas conheciam os sinais de trabalho de parto e $12 \%$ desconheciam tais sinais. No relato de uma gestante, apresentado na pesquisa de Costa et al (2011, p 552) sobre as orientações recebidas, ela diz:

(A enfermeira) falou todas as orientações como a dor que eu ia sentir, os cuidados em geral que eu tinha que ter, como evitar esforço, e o toque que iriam fazer. Me orientou em tudo, das dores que eu ia sentir, ficar mais na posição de lado esquerdo, pois seria melhor. Dicas do parto, como colocar força para baixo quando as contrações viessem, que tivesse paciência na hora do parto e que se tivesse algum sangramento fosse ao hospital.

O Protocolo Mãe Curitibana (2012) prevê ações educativas para orientar a gestante durante o pré-natal e nascimento, quanto aos sinais de alerta, sinais e sintomas do parto e como proceder nessas situações.

Evidenciado a importância do reconhecimento dos sinais de trabalho de parto, a pesquisa aponta que a maioria das entrevistadas sabia, mas algumas, mais especificamente $12 \%$, ainda não conheciam, o que demonstra a necessidade da enfermagem garantir o repasse desses conhecimentos.

Gráfico 7: Orientação quanto à realização do plano de parto na maternidade.

Foi orientada a ir na maternidade realizar plano de parto?

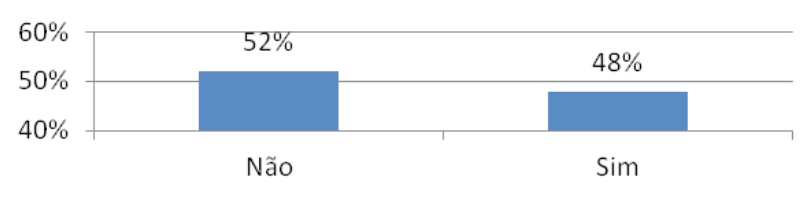

Fonte: Dados da pesquisa realizada na Maternidade do Bairro Novo com 25 gestantes de risco habitual, em maio de 2017.

Quanto à orientação para ir à maternidade realizar o plano de parto, $52 \%$ do total de entrevistadas disseram não ter sido orientadas e $48 \%$ afirmaram ter recebido a orientação. O Protocolo Mãe Curitibana (2012) diz que todas as gestantes devem ser orientadas a participar de oficinas durante o pré-natal. O plano de parto é o momento em que a gestante toma conhecimento de alguns temas, relacionados ao parto, sobre as opções que possui e escolhe, a respeito do que aprova ou não, durante os procedimentos. De acordo com Sodré et al (2010), o enfermeiro tem a obrigação ética e legal de dar informações claras e completas sobre o cuidado, os tratamentos e as alternativas, e dar à mulher a oportunidade de decidir em relação ao que lhe foi informado. A mulher, informada sobre o parto, ainda no período gestacional, apresenta-se mais segura durante a evolução do trabalho de parto e consegue participar na tomada de decisão, o que influencia, diretamente a sua satisfação em relação ao evento.

Sendo a realização do plano de parto fundamental para que a mulher adquira conhecimentos sobre os procedimentos e faça as próprias escolhas, tornando-a protagonista e deixando-a mais à vontade nesse momento importante, percebe-se que grande parte, das gestantes entrevistadas, não foi orientada a realizar o plano de parto, o que se apresenta como um ponto importante a ser melhorado. 
Gráfico 8: Orientação sobre quais motivos procurar a maternidade.

Foi orientada sobre quais motivos procurar a maternidade?

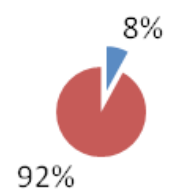

Fonte: Dados da pesquisa realizada na Maternidade do Bairro Novo com 25 gestantes de risco habitual, em maio de 2017.

Já em relação à orientação a respeito dos motivos pelos quais deviam procurar a maternidade, 92\% do total de entrevistadas afirmaram ter sido orientadas e $8 \%$ disseram não ter recebido essa orientação.

O Protocolo Mãe Curitibana (2012) estabelece que todas as gestantes devem ser orientadas a procurar a maternidade de referência, caso ocorram sinais de trabalho de parto e/ou alerta de emergência, tais como cefaleia, dor abdominal ou lombar, um edema subido, qualquer perda de líquido via vaginal, sangramento vaginal, febre, redução importante dos movimentos fetais e sinais de infecção urinária.

De acordo com o Programa Mãe Curitibana (2012), os sinais de alerta a que as gestantes precisam estar atentas e procurar a maternidade são: dores abdominais, sinais de trabalho de parto como, por exemplo, endurecimento da barriga e dores fortes e frequentes da mesma forma como ocorrem nas cólicas, inchaço do rosto ou no corpo, perda de líquido pela vagina ou sangramento, dor de cabeça e visão embaçada, diminuição preocupante da movimentação do bebê, dor para urinar, febre, vômitos persistentes, corrimento vaginal com cheiro ruim e forte ou ardência.

O ideal é que todas as gestantes tenham conhecimento dessas informações, pois são muito importantes, portanto, é preciso melhorar nesse quesito, já que $8 \%$ das entrevistadas não foram orientadas.

Gráfico 9: Temas abordados durante o pré-natal.

Os temas abaixo foram abordados durante o pré-natal?
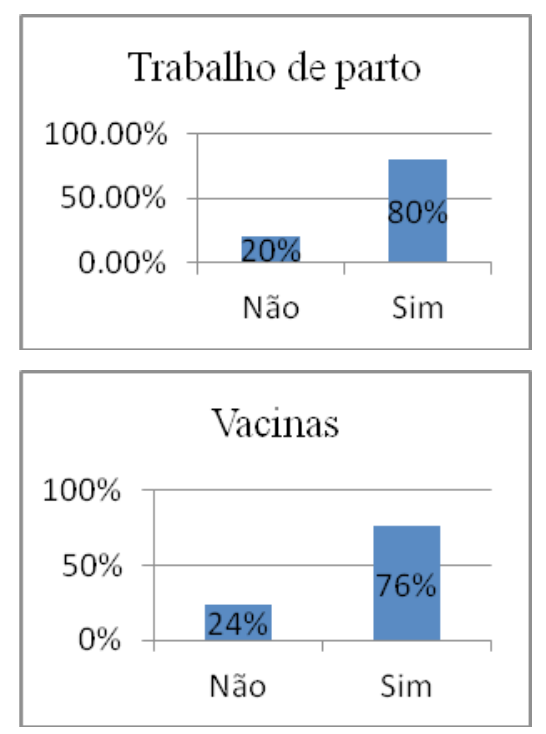
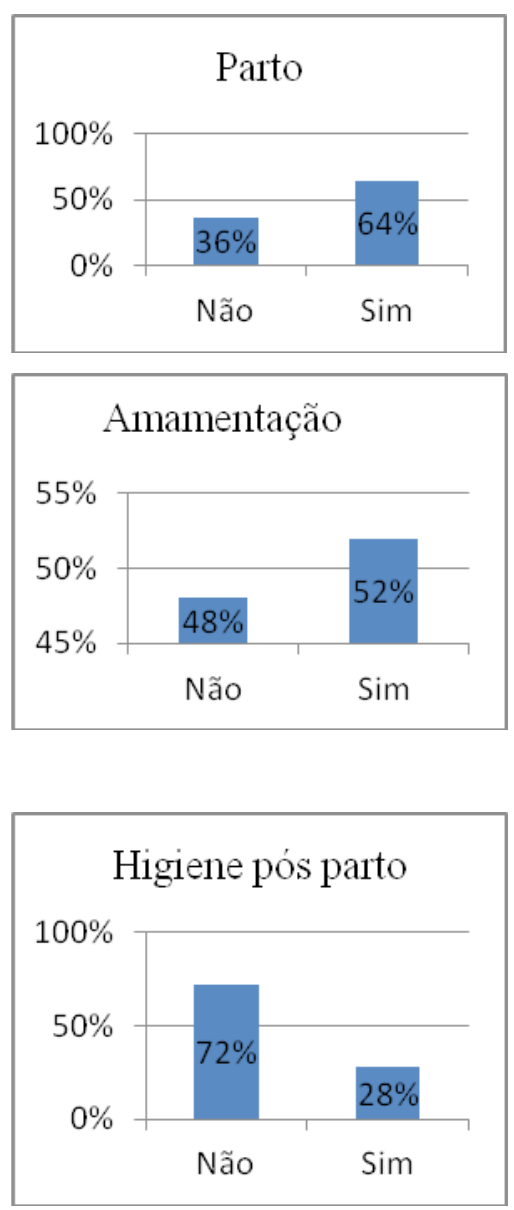
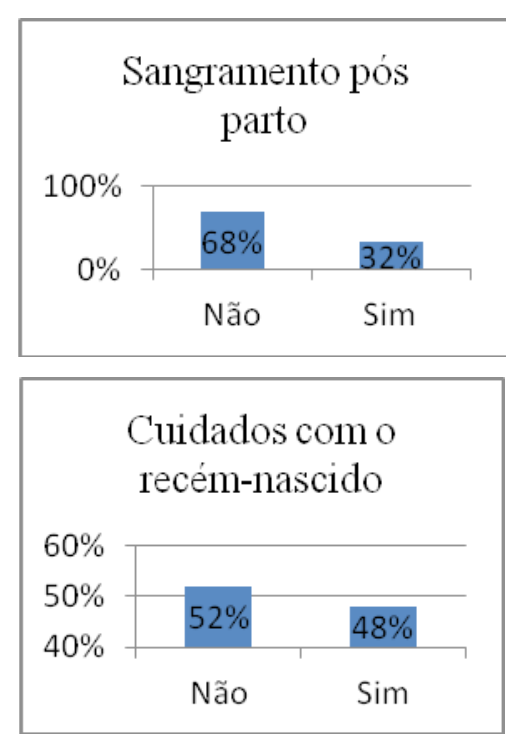
Quando perguntadas sobre os temas que foram abordados, durante o pré-natal, todas as entrevistadas responderam da seguinte forma, separado por tema: trabalho de parto, $80 \%$ afirmaram que foi abordado e $20 \%$ responderam que não parto, $64 \%$ disseram sim e $36 \%$ responderam que não foi abordado; sangramento pós-parto, $68 \%$ responderam não e $32 \%$ afirmaram ter sido abordado; vacinas, $76 \%$ responderam que foi abordado e $24 \%$ negaram; amamentação, $52 \%$ disseram sim e $48 \%$ responderam que não foi abordado; cuidados com o recém-nascido, $52 \%$ responderam não e $48 \%$ afirmaram ter sido abordado; higiene pós-parto, $72 \%$ disseram que não foi abordado no pré-natal e $28 \%$ responderam sim.

De acordo com o Protocolo Mãe Curitibana (2012), deve ser ofertada e incentivada a participação da gestante e do acompanhante nas oficinas de pré-natal, oficinas essas que abordarão todos os temas citados acima e outros, que ainda serão divididos, de acordo com a idade gestacional. O Protocolo estabelece que todas as gestantes devem ser orientadas a respeito dos temas, aqui apresentados. Santos et al (2010) dizem que atividades de educação em saúde, com as gestantes e familiares, por meio de encontros e grupos, permitem a aproximação entre profissionais e receptores do cuidado e contribuem para o oferecimento de assistência humanizada.

O conhecimento adquirido, durante o pré-natal, é fundamental para as gestantes saberem que atitudes tomar nas diversas situações que possam surgir e sentirem-se à vontade quanto aos procedimentos, sendo essa a finalidade do enfermeiro que atua disponibilizando tais conhecimentos, durante o pré-natal.

A pesquisa aponta que nos temas: trabalho de parto, parto e vacinas; a maioria das gestantes foi orientada, mas não todas. Acerca do tema amamentação, as respostas foram equilibradas, com algumas entrevistadas a mais, respondendo que foram orientadas, bem como sobre o tema - cuidados com o recém-nascido, mas com relação a esse, algumas gestantes a mais, responderam que não foram orientadas a respeito.

No que tange os temas sangramento e higiene pós-parto, a maioria das entrevistadas disse não ter sido orientada. Com base na pesquisa realizada, é nítida a necessidade de melhoria em relação a essas orientações, pois por se tratarem de temas de grande relevância e importância, o ideal é que todas as gestantes possuam conhecimento a respeito.
De acordo com Vieira et al. (2010), notam-se muitas dificuldades encontradas pelas mulheres, em seu pós-parto, relacionadas não somente à parte individual, mas também de modo psicossocial, uma vez que as parturientes necessitam da interação ativa com seus filhos, com suas famílias e com seus parceiros. Por isso, é de extrema importância que seja realizado um plano de assistência à saúde dessas puérperas, onde todos os profissionais de enfermagem apresentem o hábito de esclarecer todas as dúvidas e se certifiquem de que repassaram todas as informações necessárias para que as pacientes tenham uma boa interação e experiência com os seus recém-nascidos.

Para Strapasson e Nedel (2010), o puerpério é denominado de o segmento com mais riscos, pois é onde ocorrem as alterações, tanto fisiológicas, quanto psicológicas. Com isso, espera-se que os profissionais de enfermagem realizem cuidados com qualidade e que se preocupem com a educação em saúde, para que sejam evitadas as complicações e alterações do estado emocional das pacientes.

Como afirma Francisquini et al. (2010), a gestante que recebe todas as informações e orientações referentes ao seu pré-natal, parto e seu puerpério, sentirá mais segurança e aptidão para tomar decisões sobre o seu corpo, na hora do nascimento e no seu pós-parto, do contrário, a falta de informação acarretará dúvidas, desnecessárias ao momento. Alguns fatores são de extrema importância para serem sinalizados às puérperas, após o nascimento do bebê, tais como: insegurança emocional, ansiedade, dores e desconforto no puerpério, grande dificuldade em conseguir satisfazer seu sono e de conseguir relaxar ou repousar nesse período.

\section{CONCLUSÃO}

Levando-se em consideração que os temas abordados na pesquisa são de suma importância para as gestantes terem uma experiência plena na gestação, conhecendo os procedimentos e, inclusive, fazendo as próprias escolhas, a presente pesquisa evidencia que o serviço, prestado nas unidades de saúde, possui falhas no que tange às orientações e realização de consultas e oficinas. Sendo o ideal, a resposta afirmativa de $100 \%$ das entrevistadas a todas às questões apresentadas acima, por se tratarem de temas básicos e importantes. Em nenhuma pergunta foi atingido tal resultado e em outras, menos da metade das entrevistadas respondeu afirmativamente. 
Isso demonstra a necessidade de uma maior aproximação das unidades de saúde, onde é realizado o pré-natal com as gestantes, da enfermagem responsável por algumas consultas e pela maioria das orientações. Portanto, há espaço para consideráveis melhorias e o presente estudo apontou a necessidade de mudanças, no que diz respeito a se estabelecerem temas para campanhas e treinamentos, a fim de que seja alcançado o objetivo principal da enfermagem, que é o da assistência em geral, garantindo a entrega de um serviço completo e eficaz, que permita às pessoas sentirem-se bem. No caso do pré-natal, possibilitar às gestantes a melhor experiência possível em um momento tão especial.

\section{REFERÊNCIAS}

BARRETO, C. N.; RESSEL, L.B.; SANTOS, C.C.; WILHELM, L. A.; SILVA, S. C.; ALVES, C. N. Atenção pré-natal na voz das gestantes. Rev enferm UFPE on line, Recife, v. 7, n. 5, p. 4354-63, 2013. Disponível em: $<$ www. revista.ufp e.br/revistaenfermagem/index.p hp/revista/ article/download/.../6376> Acessado em 23 de maio de 2017.

CONITEC. Ministério da saúde. Diretriz Nacional de Assistência ao Parto Normal. 12 de Jan-2016. Disponível em: < http://conitec.gov.br/diretriz-nacional-de-atencao-aoparto-normal > Acessado em: 15 Out. 2016, 20:00:00.

COSTA, A.P.; BUSTORFF, L. A. C. V.; CUNHA, A. R.R.; SOARES, M. C. S.; ARAÚJO,V. S. Contribuições do prénatal para o parto vaginal: percepção de puérperas. Rev Rene, Fortaleza, v.12, n.3, p. 548-54, 2011. Disponível em:< http://periodic os.ufc.br/index.ph p/rene/article/ viewFile/4282/3300. >Acessado em 28 de Maio de 2017.

DUARTE, S. J. H.; BORGES, A. P.; ARRUDA, G. L. D. Ações de enfermagem na educação em saúde no prénatal: relato de experiência de um projeto de extensão da Universidade Federal do Mato Grosso. R. Enferm. Cent. O. Min, p. 277-282, 2011;. Disponível em: $<$ http://seer.ufsj. edu./index.php/rec om/article/view/13.> Acessado em $28 \mathrm{de}$ maio de 2017.

FIGUEIREDO, M. G. A. V. de.; MARQUeS, A. C. Prénatal: experiências vivenciadas pelo pai. Cogitare Enferm. v.16, n.4, p. 708-13, 2011. Disponível em: $<$ http://revi stas. ufpr.br/ cogitare/article/viewFile/26126/17395.> Acessado em 23 de maio de 2017.

FRANCISQUINI, A. R.; HIGARASHI, I. H.; SERAFIM, D.; BERCINI, L. O. Orientações recebidas durante a gestação, parto e pós-parto por um grupo de puérperas. Revista Ciência, Cuidado e Saúde, v. 9, n. 4, p. 743-751, 2010. Disponível em: http://ojs.ue m.br/oj s/index.php/
CiencCuidSaude/article/view/ 13826/7193. Acessado em 10 de junho de 2017.

LIMA, J. C.; MAIA, D. B.; ROCHA. P. C. de F.; GAMA, R. M.; LIMA, R. V. Gestação Vida: oficina educacional para gestantes com abordagem multiprofissional em uma Unidade Básica de Saúde da cidade de Manaus. Extensão em Foco, Curitiba: Editora da UFPR, n. 10, p. 86-101, 2014. ISSN 2358-7180. Disponível em: <revistas.ufpr.br/ extensao/artic le/download/28184/23826.> Acessado em 23 de maio de 2017.

MAMEDE, F. V.; MAMEDE, M. V.; DOTTO, L. M. G. Reflexões sobre deambulação e posição materna no trabalho de parto e parto. Esc Anna Nery Rev Enferm, v. 11, jun. 2007.

PROGRAMA MÃE CURITIBANA. Secretaria municipal de saúde. Pré-natal, parto, puerpério e atenção ao recémnascido. Curitiba, 2012.

REBERTE, L. M.; HOGA, L. A. K. A experiência de pais participantes de um grupo de educação para saúde no prénatal. Ciencia y EnfermerIa XVI, v.16, n.1, p.105-114, 2010. Disponível em: < http://www.scielo.cl/pdf/cienf/ v16n1/art_12.pdf. >Acessado em 23 de maio de 2017.

SANTOS, A. de L.; RADOVANOVIC, C. A. T.; MARCON, S. S. Assistência pré-natal: satisfação e expectativas. Rev. Rene, vol. 11, Número Especial, p.61-71, 2010. Disponível em: $<$ http://www.periodicos.ufc.br/index.php/rene/article/ view/4 661/3477.> Acessado em 28 de maio de 2017.

SÉ, C.C.S. Módulo acolhimento do programa cegonha carioca: uma prática reiterativa da enfermeira obstétrica. UERJ. Rio de Janeiro, 2014. Disponível em: <http:// pesquisa.bvsalud.org/oncologiauy/resource/en/int-4150.> Acessado em 28 de maio de 2017.

SODRÉ, T. M.; BONADIO, I. C.; JESUS, M. C. P.; MERIGHI, M. A. B. Necessidade de cuidado e desejo de participação no parto de gestantes residentes em LondrinaParaná. Texto Contexto Enferm, Florianópolis, v.19, n.3, p.452-60, 2010. Disponível em: <http://www.scielo.br/pdf/ tce/v19n3/a06v19n3.> Acessado em 28 de maio de 2017.

STRAPASSON, M. R.; NEDEL, M. N. B. Puerpério imediato: desvendando o significado da maternidade. Revista Gaúcha Enfermagem, Porto Alegre-RS, v. 31, n. 3, p. 521-528, 2010. Disponível em: http://www.scielo.br/ $\mathrm{pdf} / \mathrm{rgenf} / \mathrm{v} 31 \mathrm{n} 3 / \mathrm{v} 31 \mathrm{n} 3 \mathrm{a} 16$. Acessado em 10 de junho de 2017.

VIEIRA, F.; BACHION, M. M.; SALGE, A. K. M.; MUNARI, D. B. Diagnósticos de enfermagem no período pós-parto imediato e tardio. Escola Anna Nery, Revista Enfermagem, v. 14, n. 1, p. 83-89, 2010. Disponível em: http://www.s cielo.br/ pdf/ean/v14n1/v14n1a13. Acessado em 10 de junho de 2017. 
ZAMPIERI, M.F.M.; GARCIA, O.R.Z.; BOEHS, A.E.; VERDI, M. Enfermagem na Atenção Primária à Saúde da Mulher. Textos fundamentais - Série Atenção Primária - v. 2, Versão atualizada e ampliada, Florianópolis, 2010.

ZAMPIERI, M.F.M.; ERDMANN, A. L. Cuidado humanizado no pré-natal: um olhar para além das divergências e convergências. Rev. Bras. Saúde Mater. Infa nt. [online]. v.10, n.3, p.359-367 2010. Disponível em: http:// dx.doi.org/10.1590/S1519-38292010000300009. Acessado em 23 de maio de 2017. 